\title{
Influence of wet activation of used inorganic binder on cyclically refreshed water glass moulding sands hardened by microwaves
}

\author{
* Mateusz Stachowicz and Kazimierz Granat \\ Department of Foundry, Plastics and Automation, Wrocław University of Technology, Wybrzeże Wyspiańskiego 25, 50-370 Wroctaw, Poland
}

\begin{abstract}
The paper presents the research results of using an innovative method to reclaim the waste moulding sands containing water glass. Two of the examined processes are connected with "dry" or "wet" activation of inorganic binder in waste moulding sand mixtures physically hardened by microwave radiation. The sand mixtures consisting of high-silica sand and water-glass with average molar module 2.5, were subjected to the following cyclical process: mixing the components, compacting, microwave heating, cooling-down, thermally loading the mould to $800{ }^{\circ} \mathrm{C}$, cooling-down to ambient temperature, and knocking-out. After being knocked-out, the waste moulding sands were subjected to either dry or wet activation of the binder. To activate thermally treated inorganic binder, each of the examined processes employed the surface phenomenon usually associated to mechanical reclamation. The study also covered possible use of some elements of wet reclamation to rehydrate waste binder. To evaluate the effectiveness of the two proposed methods of waste binder activation, selected strength and technological parameters were measured. After each subsequent processing cycle, the permeability, tensile strength and bending strength were determined. In addition, the surface of activated sand grains was examined with a scanning electron microscope. Analysis of the results indicates that it is possible to re-activate the used binder such as sodium silicate, and to stabilize the strength parameters in both activation processes. Permeability of the refreshed moulding sands strongly depends on the surface condition of high-silica grains. The wet activation process by wetting and buffering knocked-out moulding sands in closed humid environment makes it possible to reduce the content of refreshing additive in water-glass. The moulding sands cyclically prepared in both processes do not require the addition of fresh high-silica sand. The relatively high quality achieved in the refreshed moulding sands allows them to be reused for manufacture of next moulds. Thus, the two proposed methods for cyclically processing used moulding sands containing sodium silicate, subject to microwave hardening, are suitable for economic and ecological circulation moulding mixtures.
\end{abstract}

Key words: moulding sand; reclamation; water-glass; microwave heating; refreshing
CLC numbers: TG221 .2
Document code: $\mathrm{A}$
Article ID: 1672-6421(2016)06-427-06

\begin{abstract}
Sodium silicate (i.e. water-glass), an inorganic binder applied in foundry industry, is characterised by low cost and low harmfulness. However, it has considerable disadvantages such as poor knocking-out properties ${ }^{[1]}$, tough casting cleaning with used moulding sand and difficult waste sand reclamation.

It is hard to find examples in literature concerning the effective reclamation of water-glass moulding sands, which can activate the waste binder and restore their
\end{abstract}

\footnotetext{
*Mateusz Stachowicz

Male, born in 1982, Ph.D. Eng. Manager of Molding Sands Research Laboratory in Wrocław University of Technology. His research activities are focused on foundry moulding and core sands, die casting process, drying equipment and microwave heating applications in the foundry industry.

E-mail: Mateusz.Stachowicz@pwr.edu.pl
}

Received: 2015-12-05; Accepted: 2016-08-11 initial bonding properties. One example of refreshing by cooling and moistening appears to be a proper process for green moulding sands ${ }^{[2]}$. The reported refreshable moulding sand mixtures other than green moulding sands are those containing a polymeric binder such as $\mathrm{BioCo}_{2}{ }^{[3]}$. In the case of microwave hardening, it was possible to restore the initial bonding properties prior to the cross-linking process. Reclamation of the $\mathrm{BioCo}_{2}$ binder was performed by complementing composition of the moulding mixture with proper amount of refreshing water. Literature data about reclamation of bonding materials like sodium silicate are hardly available. An exception is the Ref. [4, 5], where preliminary research results were presented on the possibility to reclaim inorganic binder in waste moulding sands containing sodium silicate, microwave hardened or traditionally dried ${ }^{[6]}$. The refreshing process was carried out in the chamber of a laboratory roll mixer. Mixing and crushing 
result in the secondary hydration of the binder. To maintain and stabilize the mechanical and technological parameters, it appears necessary to add small amounts of fresh components of the moulding mixture, including the binder. Introducing specific refreshing additives enabled starting the so-far unexplained mechanisms to activate the film of thermally treated binder, covering the surfaces of high-silica grains.

The most up-to-date and technologically advanced descriptions concerning utilising the secondary hydration of water-glass can be found in patents and patent applications. The most often described methods include the wet reclamation of high-silica base sand by secondary hydration of chemically hardened inorganic binders. An example is given in one patent application ${ }^{[7]}$ where used moulding sand containing water-glass, disinteg ated in a vib ating mill, is reclaimed $\$$ rinsing with water at $90{ }^{\circ} \mathrm{C}$. The preliminarily cleaned base sand is subjected to intensive stirring in water. Another patent application ${ }^{[8]}$ indicates that secondary hydration can be also affected, apart from intensive wetting, by keeping the moulding mixture in a container at a higher pressure and the cleaning of the sand is performed by purging it with overheated water steam, like in the application in Ref. [9]. Other patent applications ${ }^{[10,11]}$ described the processes where used moulding mixture is subjected to dry and/or wet reclamation in special buffer tanks ${ }^{[12,13]}$ designed for removing the reacted binder.

The latest development of technology of moulding sands containing water-glass is mainly focused on manufacture of innovative and economical reclamation appliances and on determining parameters of the methods guaranteeing effective separation of the film of physically and chemically hardened, overheated bonding materials present on surfaces of base grains ${ }^{[14,15,16,17]}$. Other studies on moulding sands containing water-glass are focused on improving their knockingout properties. Among them, using special additives ${ }^{[18]}$ or limiting binder volume in the moulding mixture was mentioned, supported by an advanced hardening process ${ }^{[19,20,21]}$. The modern way of manufacturing casting moulds and cores of moulding sands containing water-glass, which employs hardening by economical and eco-friendly microwave heating, may change the current classification of the binder. Based on previous research, the hardening by microwave heating makes it possible to obtain very good mechanical and technological parameters of moulding mixtures, with very limited content of water-glass to only $1.5 \%^{[22]}$.

The research was aimed at evaluating the methodology of reclaiming microwave-hardened moulding sands containing water-glass. The waste moulding sand was first wetted and buffered in a closed chamber. This treatment triggers the "wet activation" of the film, the hydrophilic binder deposited on the silica sand surface. The processes of the binder reclamation by mechanical "dry activation" or "wet activation" are shown in Fig. 1, and the obtained results are evaluated by means of selected mechanical criteria designed for fresh moulding sands. However, influences of other factors, such as buffering time in the closed humid environment at constant temperature and pressure are still unexplained. The purpose of the proposed methodology of activation is to restore the bonding properties of the used binder with a high efficiency.

As a base for the laboratory examinations, it was assumed that, by proper selection of the process parameters and introduction of an experimentally determined small quantity of refreshing components (see Fig. 1), it will be possible to employ the microwave-hardened moulding mixture containing grade 145 sodium silicate as the circulating moulding sand, which is of a $\mathrm{g}$ eat impr tance from th economical, ecolog cal and technological points of view.

\section{Experimental procedure}

Based on the previous research ${ }^{[4,5]}$, the content of the waterglass grade 145 (average molar module $=2.5$ ) in fresh moulding sands was set at $1.5 \mathrm{wt} . \%$. Moreover, to improve spreading ability of the binder on surfaces of the high-silica sand, $0.5 \mathrm{wt} . \%$ of water was added to the ribbon laboratory mixer during the preparation of the moulding sands (Stage 0). The specimens for mechanical testing were made in a box specially adapted for work in electromagnetic field ${ }^{[23]}$. The specimens and moulds made of fresh moulding mixtures were cooleddown after rapid microwave hardening. Next, the moulds were thermally loaded at $800{ }^{\circ} \mathrm{C} \pm 5{ }^{\circ} \mathrm{C}$ (Stage VI), as shown in Fig. 1. In this way, a specific degree of thermal load (overheating range between: minimum at $100 \pm 5{ }^{\circ} \mathrm{C}$ and maximum at 800 $\pm 5{ }^{\circ} \mathrm{C}$ ) was achieved for the first time. After cooling down the moulds to about $40{ }^{\circ} \mathrm{C}$, the used and preliminarily reclaimed moulding sands (Stage VII) underwent one of the two proposed reclamation processes.

The first process, described in details in Ref. [4, 5] referred as "dry activation", consisted of dry mechanical activation of glassy sodium silicate using a disintegrating and grinding device, accompanied by controlled continuous removing of the created dusty fractions (Stage I). The second method so called "wet activation" began from wetting (with addition of water at $2.3 \mathrm{wt} . \%$ ) the knocked-out waste moulding sand and buffering it at ambient temperature in a closed chamber for 240 minutes (Stage I). At "Stage II", elements were introduced to initiate mechanical activation of grain surfaces such as intensive mixing with stirring. At "Stage III", a small amount (about $0.6 \mathrm{wt} . \%$ ) of refreshing binder (see Fig. 1) of the same grade was introduced. During each of five processing cycles, tensile and bending strength values, $R_{\mathrm{m}}^{\mathrm{U}}$ and $R_{\mathrm{g}}^{\mathrm{U}}$ and permeability of both reclaimed sands were determined after the "Stage IV". On the basis of these examinations, an attempt was made to determine the number of the reclamation cycles during both activation processes in laboratory conditions.

\section{Results}

Test results after "Stage IV", combined with their linear regression, are shown in Figs. 2, 3 and 4. The cycle "0" marked on abscissa describes the parameters of the fresh and microwave 
Dry activation process

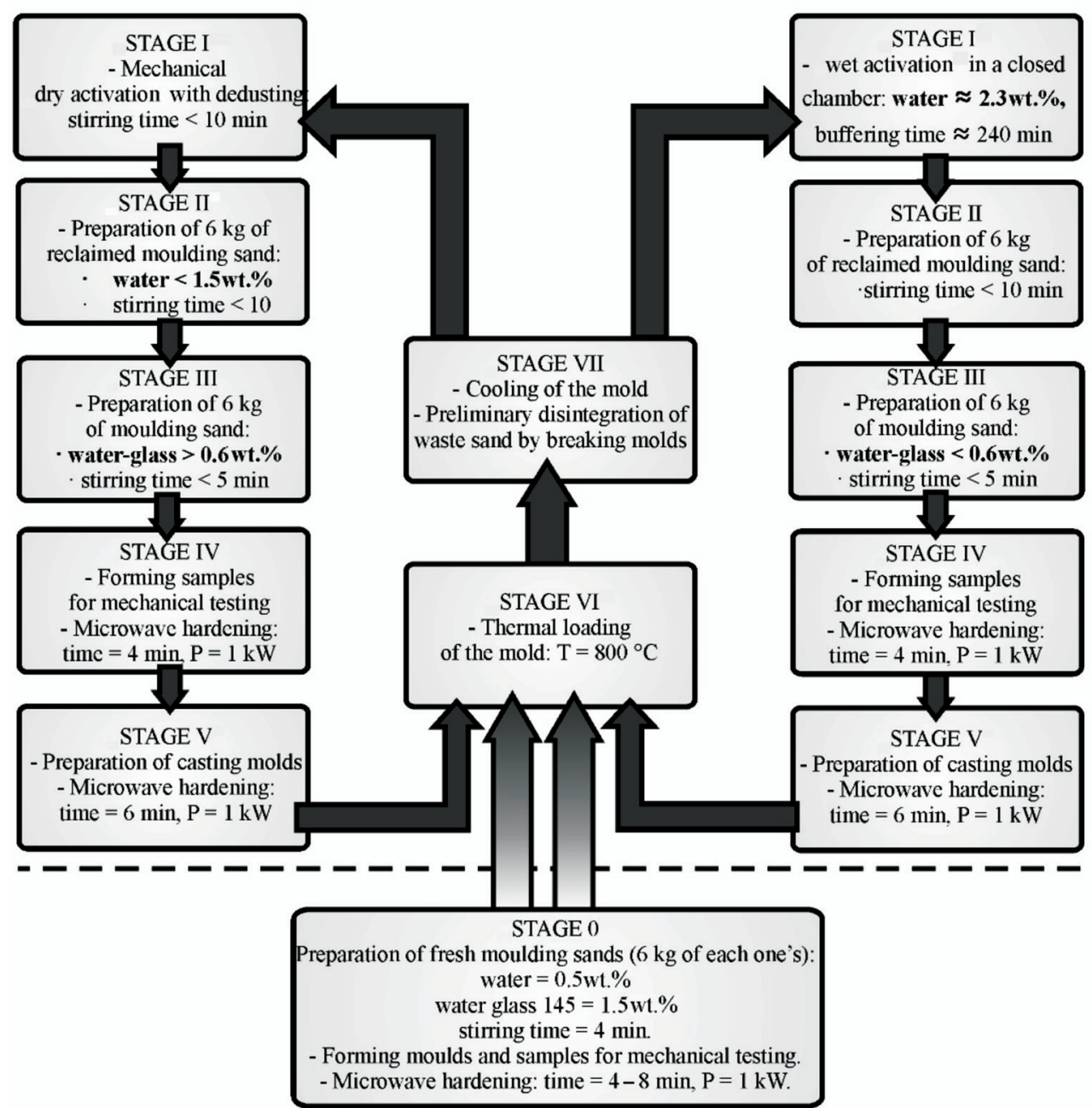

Fig. 1: Schematic presentation of two processing cycles of dry activation ${ }^{[4,5]}$ or wet activation of waste moulding sands in laboratory conditions with specific amounts of refreshing additives

hardened sands.

Taking into account mechanical parameters of the cyclically processed moulding mixtures, it is possible - by proper selection of activation methods (wet or dry) and sequence of operations, to indicate that the effective reclamation based on wet activation can be carried out at least five times (Figs. 2 and 3). In each of

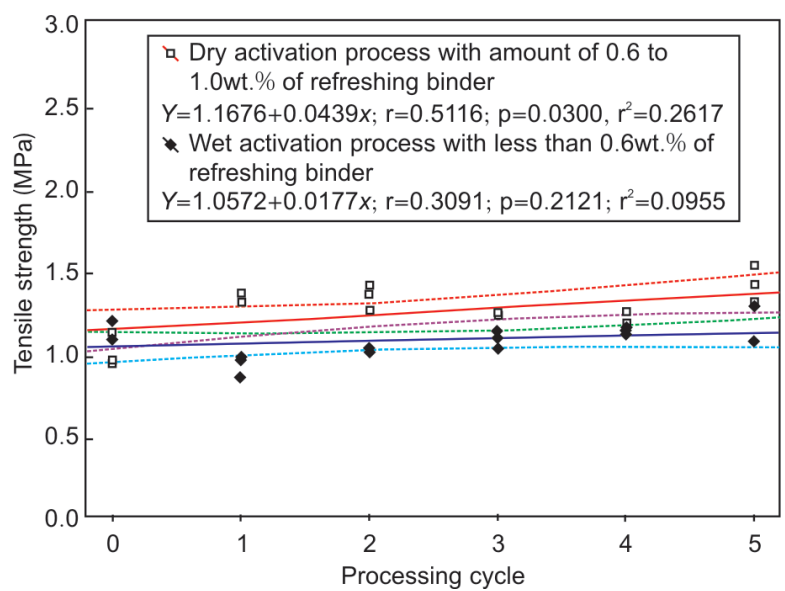

Fig. 2: Tensile strength $R_{\mathrm{m}}{ }^{\mathrm{U}}$ of activated and refreshed moulding mixtures after "Stage IV" in each of five processing cycles

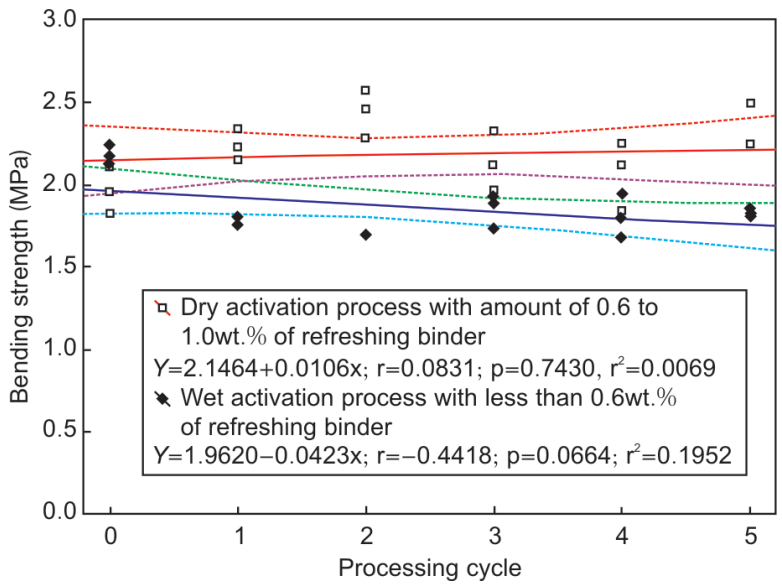

Fig. 3: Bending strength $R_{\mathrm{g}}{ }^{U}$ of activated and refreshed moulding mixtures after "Stage IV" in each of five processing cycles

the proposed activation processes, it is possible to maintain the mechanical properties of the cyclically refreshed moulding sands by refreshing them with constant quantities of water and binder. However, the proposed linear regression models show relatively low correlation coefficients, which can be associated with various degrees of overheating ${ }^{[6]}$ in each cycle. It can be assumed 


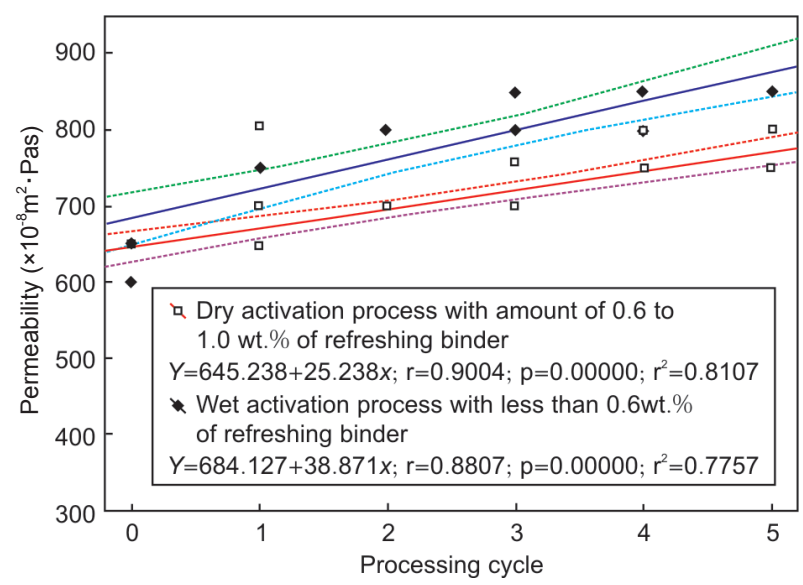

Fig. 4: Permeability $P^{\cup}$ of activated and refreshed moulding mixtures after "Stage IV" in each of five processing cycles

that other methods of approximation, like polynomial, would be more matched. But, the primary objective to stabilize the test technological and strength parameters have been achieved.

The wet activated moulding mixture consistently has lower values of tensile and bending strength. The difference may result from a few reasons. The first one noticed is the small difference between initial strength values measured for both fresh moulding mixtures in cycle "0" (see Figs. 2 and 3). Moreover, due to hygroscopicity of the binder resulting from its hydrophilic nature, refreshing addition of the binder in the wet activation process could be reduced to less than $0.6 \mathrm{wt} . \%{ }^{[24]}$. To evaluate the effectiveness of the wet activation, attention should also be paid to the addition of fresh water introduced to rehydrate the thermally treated binder. The content of water introduced to the knockedout and buffered waste moulding mixture is nearly $1 \mathrm{wt} . \%$ higher (Fig. 1) than that in the dry activated process. Higher effectiveness of wet activation does not fully compensate the small losses in case of bending strength (Fig. 3). Water addition ${ }^{[25]}$ also changes rheological properties of each moulding sand during the preparation of specimens for tensile and bending tests (in Stage IV), which is reflected in technological parameters such as permeability of the activated moulding sands.

The permeability trend line (Fig. 4) of the wet activated moulding sand shows faster growth than that of dry activation. It should be also noted that higher dynamism of permeability changes of wet activated moulding mixtures can be also caused by surface-activated linking bridges that were not properly rubbed-off during mechanical dry activation, which is confirmed by subsequent SEM observations.

The SEM images of sand grains analysed after "Stage I" in each of the wet activation cycles show repeatable coating of sand grains with the binder (Fig. 5), which is followed by intensive mixing and stirring at "Stage II". As the previous studies showed ${ }^{[4,5,6]}$, it is important to keep the film of binder remained after effective disintegration of waste moulding sand, which is susceptible to rehydrating. The observations of the reclamation after the second, third, fourth and fifth processing cycles revealed larger numbers of conglomerates of silica grains. This phenomenon may also explain the increase in permeability $\mathrm{P}^{\mathrm{U}}$ (Fig. 4), particularly pronounced in the case of the refreshed moulding sand subjected to wet activation. These observations suggest necessary modifications in stirring parameters of reclaimed moulding mixtures (Fig. 1), which are
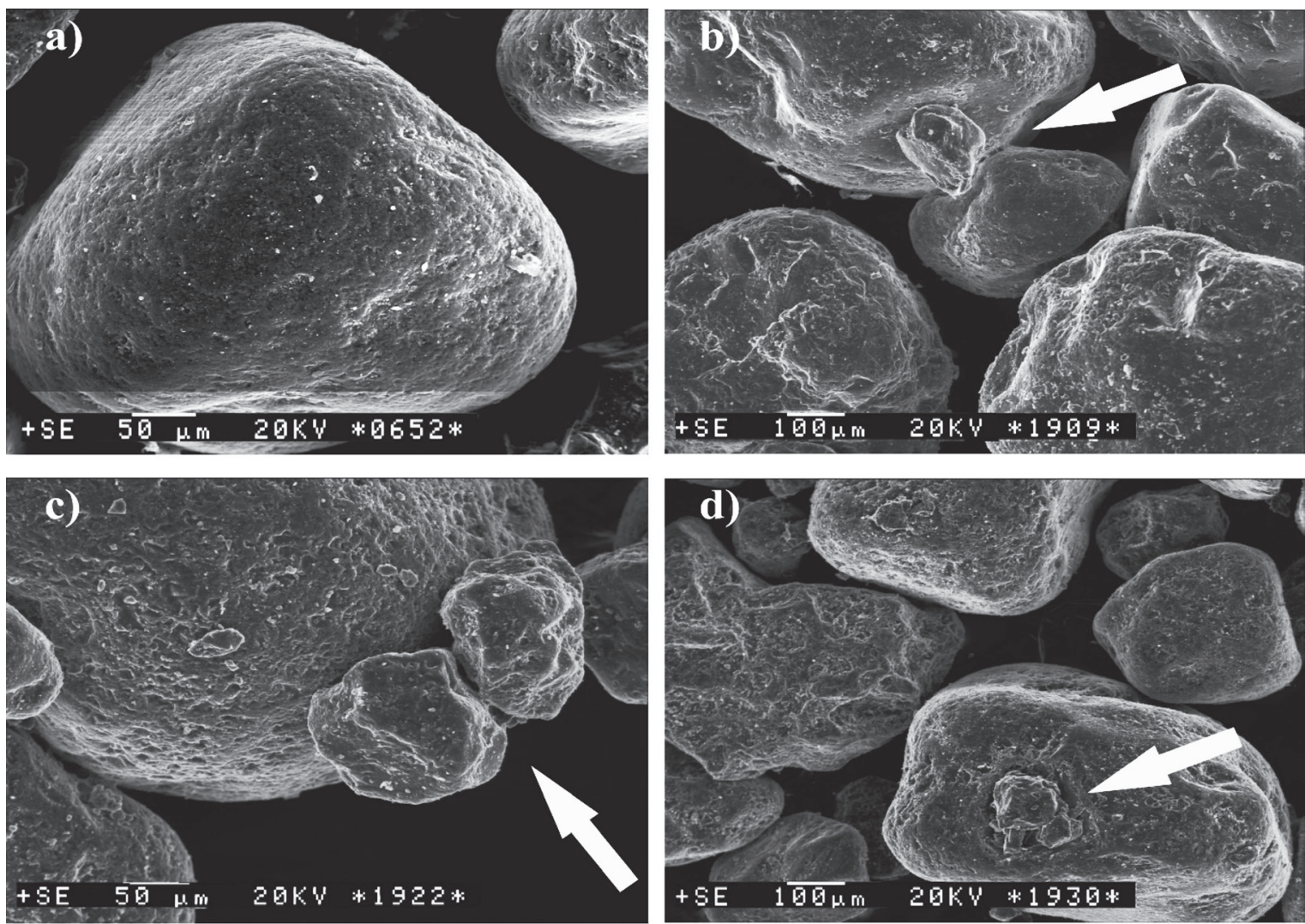

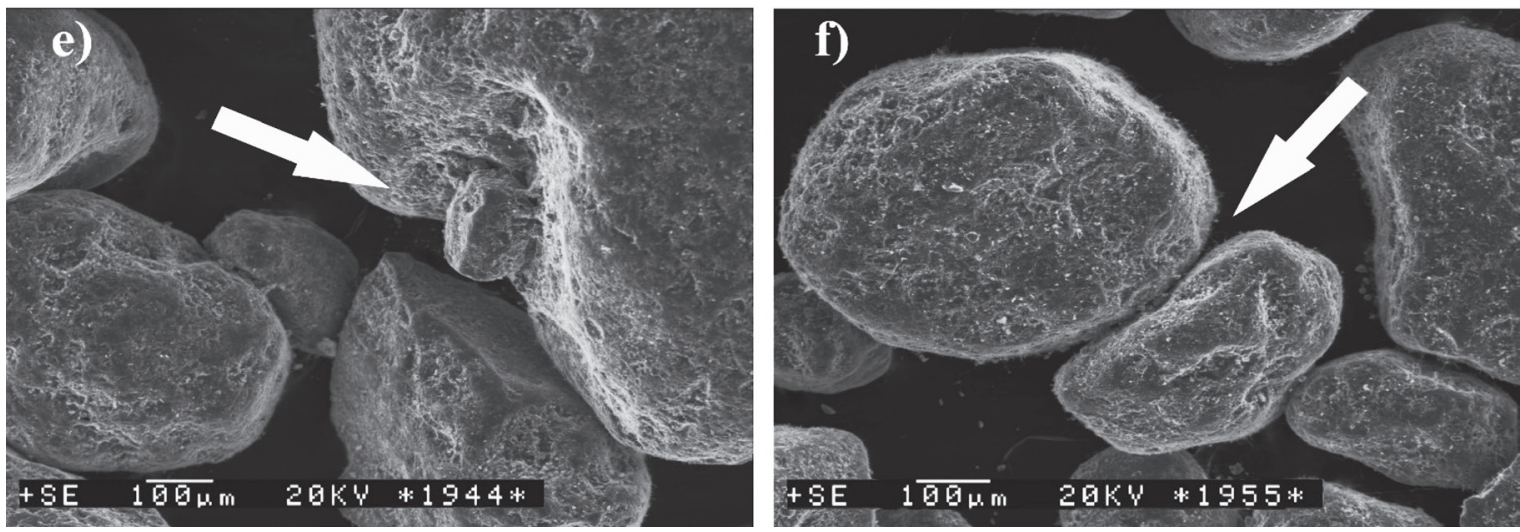

Fig. 5: SEM images of high-silica base. Conglomerates and concentration places of wet activated film of glassy sodium silicate are marked with arrows: (a) fresh high-silica sand; (b) after first cycle; (c) after second cycle; (d) after third cycle; (e) after fourth cycle; (f) after fifth cycle of reclamation

now insufficient for complete disintegration of the regenerate.

Introducing to the moulding mixture small quantities of fresh components (water and refreshing binder) at the stages I, II and III can intensify the dry mechanical process of binder reclamation containing secondary hydration (rehydration) of sodium silicate film, designated by the authors as the operation of "activation". Small addition of water makes it possible to start some of the unclear mechanisms of activating film of microwave-hardened binder. Experimentally determined amounts of the activating and refreshing additives can be treated as a starting point to improve the proposed methods of processing waste moulding sands. At the current level of knowledge, these innovative technologies of processing and activating moulding mixtures containing water-glass and hardened by physical methods, require further studies, including on knocking-out properties of refreshed moulding mixtures, their residual strength and abrasion resistance. Full explanation of all the phenomena accompanying cyclic processing of these moulding sands, as well as on the relation between $\mathrm{pH}$ of regenerate and quality of castings, provides a base to carry out technological tests outside the laboratory, which the authors currently consider.

\section{Conclusions}

(1) The present research on the possibility to refresh inorganic binders confirmed the occurrence of the secondary hydration (rehydration) phenomenon under the influence of dry or wet activation of waste moulding sands containing water-glass and hardened by microwaves.

(2) The preliminary laboratory research indicated the importance of keeping waste moulding sand in a closed chamber for effective activation of waste binder. The research should be supplemented by knowledge about influence of buffering time.

(3) In both suggested activating methods, it is critical to keep the film of binder remained after effective disintegration of waste moulding sand, which is susceptible to rehydration.

(4) In the suggested dry activation by mechanical reclamation combined with dedusting, the observed higher loss of used binder should be compensated by larger amount of refreshing sodium silicate.

(5) The amount of the refreshing water should be associated with the methods of processing waste moulding sands, i.e. the cyclically wet activated and refreshed moulding sand requires less addition of binder $(<0.6 \mathrm{wt} . \%)$ thanks to buffering in a closed chamber, which permits a more effective process of binder rehydration.

(6) Introduction of small quantity of fresh "activating" components (water and binder) makes it possible to maintain the mechanical and technological parameters of refreshed moulding mixtures during the five processing cycles. Better stabilisation of mechanical and technological parameters requires a deeper understanding on the wet activation process.

(7) Cyclically prepared moulding sand does not require the addition of fresh high-silica sand, because the quality of the obtained reclaim (base and binder) permits its $100 \%$ use as next moulding sands.

\section{References}

[1] Stanislaw M. Dobosz, Katarzyna Major-Gabryś. Glassex new additive to improve knock-out properties of sandmixes containing water-glass. Archives of Foundry Engineering, 2004, 4 (13): 63-68. (In Polish).

[2] Jan Lech Lewandowski. Materials for casting molds. Kraków, Scientific Publishing House Akapit, 1997. (In Polish).

[3] Beata Grabowska, Mariusz Holtzer, Rafał Dańko, et al. New BioCo binders containing biopolymers for foundry industry. Metalurgija, 2013, 52(1): 47-50.

[4] Mateusz Stachowicz, Kazimierz Granat. Possibilities of reclamation microwave-hardened moulding sands with water glass. Archives of Metallurgy and Materials, 2014, 59(2): 757760.

[5] Mateusz Stachowicz, Kazimierz Granat. Research on reclamation and activation of moulding sands containing water-glass hardened with microwaves. Archives of Foundry Engineering, 2014, 14(2): 105-110.

[6] Mateusz Stachowicz. Effect of overheating degree on activation efficiency of water-glass containing sandmix hardened by traditional drying. Archives of Foundry Engineering, 2015, 15(spec iss. 2): 77-82. 
[7] Qingdao Sanheshan Casting Group Co Ltd, Recycling regenerating method of water glass used sand, China Patent, CN103056291 (A), 2013-04-24.

[8] Wuhan Textile University, Combined treatment method for used water glass sand reclamation and reclamation treating liquid concentration, China Patent, CN102974757 (A), 201303-20.

[9] Jijun Lu. Reclamation method of used sodium silicate sand, China Patent, CN102527929 (A), 2012-07-04.

[10] Yingxian Zhang. Reclaimed sodium silicate core sand and application methods thereof, China Patent, CN102233403 (A), 2011-11-09.

[11] Tianjin Aukang Building Decoration Engineering Co Ltd. Used water glass sand regeneration method, China Patent, CN102078915 (A), 2011-06-01.

[12] Shiyan Feiyuan Automobile Parts Co., Ltd. Recovery and reuse method for used sodium silicate sand, China Patent, CN101462731 (A), 2009-06-24

[13] Nagasaki Prefecture. Method for reconditioning and recovering sodium silicate molding sand, Japan Patent, JPH06344076 (A), 1994-12-20.

[14] Rafał Dańko. Work of destruction of intergranular bonds in mechanical reclamation process of used-up moulding sands. Archives of Mechanical Technology and Automation, 2009, 29 (3), 23-32 (in Polish).

[15] Józef Dańko, Rafał Dańko, Mariusz Łucarz. Processes and equipment for reclamation of base of used-up moulding sands. Kraków, Scientific Publishing House Akapit, 2007, (in Polish)

[16] Józef Dańko, Jadwiga Kamińska, Mateusz Skrzyński. Reclamation of spent moulding sands with inorganic binders in the vibratory reclaimer Regmas. Archives of Metallurgy and Materials, 2013, 58 (3): 993-996.

[17] Mariusz Łucarz. Effect of intensity of mechanical reclamation operations on condition of high-silica base. In: Proceedings of the 21st Foundry Conference Technical 2008, Nowa Sól, 2931.05.2008. (in Polish).

[18] Stanisław M. Dobosz, Petr Jelínek, Katarzyna Major-Gabryś. Development tendencies of moulding and core sands. China Foundry, 2011, 8(4): 438-446.

[19] Mateusz Stachowicz, Kazimierz Granat, Daniel Nowak. Influence of water-glass grade and quantity on residual strength of microwave-hardened moulding sands. Part 1. Archives of Foundry Engineering, 2011, 11(1): 93-98.

[20] Mateusz Stachowicz, Kazimierz Granat, Daniel Nowak. Influence of water-glass grade and quantity on residual strength of microwave-hardened moulding sands. Part 2. Archives of Foundry Engineering, 2011, 11(2): 143-148.

[21] Wang Jina, Fan Zitian, Zan Xiaolei, et al. Properties of sodium silicate bonded sand hardened by microwave heating. China Foundry, 2009, 6(3):191-196.

[22] Mateusz Stachowicz, Kazimierz Granat, Daniel Nowak. Studies on the possibility of more effective use of water glass thanks to application of selected methods of hardening. Archives of Foundry Engineering, 2010, 10(2): 135-140.

[23] Mateusz Stachowicz, Beata Opyd, Kazimierz Granat. Comprehensive Assessment of Polymeric Materials for Foundry Tooling Used in Microwave Field. Archives of Metallurgy and Materials, 2015, 60(1): 335-339.

[24] Mateusz Stachowicz. Possibilities of Waste Binder Reclamation Using the Example Of Moulding Sands with Water Glass Hardened by the Conventional Drying Process. Prace Instytutu Odlewnictwa (Transactions of the Foundry Research Institute), 2015, 55(2): 29-41.

[25] Mateusz Stachowicz, Kazimierz Granat, Łukasz Pałyga. The Effect of Wetting Agent on the Parameters of Dry Moulding Silica Sands Bonded with Sodium Water Glass. Prace Instytutu Odlewnictwa (Transactions of the Foundry Research Institute), 2015, 56(1): 43-55. 